\title{
Methyl-coenzyme $M$ reductase $A$ as an indicator to estimate methane production from dairy cows
}

\author{
M. A. Aguinaga Casañas,, ${ }^{*}$. Rangkasenee, ${ }^{*}$ N. Krattenmacher, $†$ G. Thaller, $†$ C. C. Metges, ${ }^{\star}$ and B. Kuhla*1 \\ *Institute of Nutritional Physiology "Oskar Kellner," Leibniz Institute for Farm Animal Biology (FBN), Wilhelm-Stahl-Allee 2, 18196 Dummerstorf, \\ Germany \\ †Institute of Animal Breeding and Husbandry, Christian-Albrechts-University, Hermann-Rodewald-Straße 6, D-24118 Kiel, Germany
}

\section{ABSTRACT}

The evaluation of greenhouse gas mitigation strategies requires the quantitative assessment of individual methane production. Because methane measurement in respiration chambers is highly accurate, but also comprises various disadvantages such as limited capacity and high costs, the establishment of an indicator for estimating methane production of individual ruminants would provide an alternative to direct methane measurement. Methyl-coenzyme M reductase is involved in methanogenesis and the subunit $\alpha$ of methyl-coenzyme $\mathrm{M}$ reductase is encoded by the $m c r A$ gene of rumen archaea. We therefore examined the relationship between methane emissions of Holstein dairy cows measured in respiration chambers with 2 different diets (high- and medium-concentrate diet) and the mcrA DNA and mcrA cDNA abundance determined from corresponding rumen fluid samples. Whole-body methane production per kilogram of dry matter intake and mcrA DNA normalized to the abundance of the rrs gene coding for $16 \mathrm{~S}$ rRNA correlated significantly when using qmcrA primers. Use of qmcrA primers also revealed linear correlation between $m c r A$ DNA copy number and methane yield. Regression analyses based on normalized $m c r A$ cDNA abundances revealed no significant linear correlation with methane production per kilogram of dry matter intake. Furthermore, the correlations between normalized mcrA DNA abundance and the rumen fluid concentration of acetic and isobutyric acid were positive, whereas the correlations with propionic and lactic acid were negative. These data suggest that the mcrA DNA approach based on qmcrA primers could potentially be a molecular proxy for methane yield after further refinement.

Key words: methane, mcrA gene, respiration chamber, volatile fatty acids, dairy cow

Received January 5, 2015.

Accepted February 24, 2015

${ }^{1}$ Corresponding author: b.kuhla@fbn-dummerstorf.de

\section{INTRODUCTION}

Enteric methane is an end product of the anaerobic microbial fermentation of feeds generated predominantly within the rumen and, to a lesser extent, in the hindgut of ruminants. Total $\mathrm{CH}_{4}$ production ( $\mathrm{L}$ or $\mathrm{MJ} / \mathrm{d}$ ) increases with greater DMI; however, $\mathrm{CH}_{4}$ production as a proportion of DMI or gross energy intake decreases as DMI increases (Knapp et al., 2014). Loss of $\mathrm{CH}_{4}$ attributes to a 2 to $12 \%$ loss of gross energy intake, resulting in less efficient energy utilization by the animal (Johnson and Johnson, 1995). Conversely, enteric $\mathrm{CH}_{4}$ generated in the gastrointestinal tract of livestock is the single largest source of anthropogenic $\mathrm{CH}_{4}$ contributing to greenhouse gas emissions (Knapp et al., 2014). Therefore, reducing $\mathrm{CH}_{4}$ emission has both ecological and economic importance.

In studies investigating mitigation strategies, various methods to quantify methane emissions from ruminants have been applied (Bhatta et al., 2007). Measurements in respiration chambers are highly precise and accurate, allowing quantitative measurements of methane emissions continuously over a longer period of time (Derno et al., 2013). Conversely, drawbacks of this method include a limited capacity, restricting the number of animals that can be studied at the same time, and the expenses for establishment and maintenance of the chambers. In addition, housing animals in respiration chambers restricts their natural behavior, with the consequence that the results obtained may not simply be transferred to free-ranging animals (Storm et al., 2012). Therefore, an urgent need exists to identify and validate indirect indicator traits that can be used as a proxy to estimate methane production from individual ruminants.

Carbohydrate fermentation in the rumen results in the production of VFA (with acetic, propionic, and butyric acids predominating), $\mathrm{CO}_{2}$, and $\mathrm{CH}_{4}$ (Mitsumori and Sun, 2008); this process involves a wide diversity of ruminal microorganisms whose composition may shift due to the type of carbohydrate (Belanche et al., 2012). Among them, a variety of methanogenic archaea, termed methanogens, participate in the final 
stage of carbohydrate degradation converting $\mathrm{H}_{2}$ and $\mathrm{C} 1$ compounds, such as formate, $\mathrm{CO}_{2}$, or methyl donors, to produce $\mathrm{CH}_{4}$ (Leahy et al., 2013; Poulsen et al., 2013). The final step of biological methane synthesis is catalyzed by the enzyme methyl-coenzyme $\mathrm{M}$ reductase (MCR). This enzyme complex is thought to be unique to methanogens (Thauer, 1998). The protein MCR comprises 3 subunits $(\alpha, \beta$, and $\gamma$ ). The MCR $\alpha$-subunit is encoded by the mcrA gene, which is highly conserved among all methanogens, suggesting this gene to be a suitable target for quantitative detection in PCR-based methods (Grabarse et al., 2000; Li et al., 2012) and possibly a quantitative indicator for methane yield. The aim of the present study was to assess the relationship between $\mathrm{CH}_{4}$ emissions of Holstein cows measured in respiration chambers and the quantity and activity of methanogens in the rumen using quantitative PCR detection of genomic DNA and RNA transcripts of the mcrA gene relative to the rrs gene coding for $16 \mathrm{~S}$ rRNA.

\section{MATERIALS AND METHODS}

\section{Animals, Feeding, Rumen Fluid Sampling, and $\mathrm{CH}_{4}$ Measurement}

All animals were treated in accordance with the guidelines for the use of animals as experimental subjects of the State Government in MecklenburgWestern Pomerania (Registration No. LALLF M-V/ TSD/7221.3-1.1-034/12). During early lactation, 10 German Holstein dairy cows entering the first ( $\mathrm{n}=$ 4) or second lactation $(\mathrm{n}=6)$ were fed twice daily at 0700 and $1530 \mathrm{~h}$ a TMR with a high concentrate (HC) content (Table 1) until 104 DIM. The diet formulation was calculated according to the recommendations of the German Society of Nutrition Physiology (GfE, 2004). Animals were housed in a freestall barn unless they were halter-trained and adapted to the respiration chambers (habituation at least 3 times, eating, drinking, ruminating, laying down).

On 100 DIM, a rumen fluid sample was taken via a rumen tube introduced via the esophagus. One rumen fluid sample from 1 cow fed the HC diet could not be obtained. Subsequently, the body mass was determined and cows were transferred to open-circuit respiration chambers in which gas exchange equilibration was achieved overnight. In the chamber, cows were kept at ambient temperature at $15^{\circ} \mathrm{C}, 60 \%$ relative humidity, and a light cycle ranging from 0600 to $1900 \mathrm{~h}$. Cows were milked twice daily at 0700 and $1530 \mathrm{~h}$ and had free access to water (Derno et al., 2013). On 101 DIM, a feed sample was taken for analysis (Table 1) and ad libitum feed intake was recorded every $6 \mathrm{~min}$ for $24 \mathrm{~h}$ by feed disappearance measured by a scale connected to an electronic registration device. Methane concentration was measured at intervals of $6 \mathrm{~min}$ for $24 \mathrm{~h}$ by infrared-absorption (Sidor, Sick Maihak, Reute, Germany).

After the stay in the respiration chamber, cows were transferred back to the freestall barn. From 105 DIM onwards (mid lactation), cows received a TMR containing a medium concentrate (MC) portion (Table 1) meeting the requirements defined by the German Society of Nutrition Physiology (GfE, 2004). On 138 DIM, when cows were on the MC diet, a rumen fluid sample was taken and cows were transferred to respiration chambers to measure $\mathrm{CH}_{4}$ production as described above.

Table 1. Ingredients and chemical composition of high-concentrate (HC) and medium-concentrate (MC) diets

\begin{tabular}{lcc}
\hline & \multicolumn{2}{c}{ Diet } \\
\cline { 2 - 3 } Component & HC & MC \\
\hline Ingredient, g/kg of DM & 217 & 279 \\
Grass silage & 317 & 177 \\
Corn silage & 16 & - \\
Alfalfa hay & 5 & - \\
Alfalfa silage & - & 42 \\
Hay & - & 83 \\
Straw & $368^{1}$ & 131 \\
Dried beet pulp & 55 & $614^{2}$ \\
Concentrate & $22^{3}$ & $10^{4}$ \\
Extracted soybean meal, 44\%XP & 178 & 99 \\
Mineral feed & 50 & 61 \\
Chemical analysis & 162 & 153 \\
Starch, g/kg of DM & 44 & 27 \\
Sugar, g/kg of DM & 170 & 190 \\
Utilizable CP, ${ }^{5}$ g/kg of DM & 7.2 & 6.7 \\
Crude fat, g/kg of DM & 324 & 349 \\
Crude fiber, g/kg of DM & 210 & 205 \\
NEL, MJ/kg of DM & & \\
NDF, g/kg of DM & & \\
ADF, g/kg of DM &
\end{tabular}

${ }^{1} \mathrm{HaGe}$, Rendsburg, Germany: 20\% sugar beet pulp, $32 \%$ rape expeller, $12 \%$ wheat bran, $11 \%$ rapeseed meal, $10 \%$ corn meal, $10 \%$ extracted soy meal, $5 \%$ molasses.

${ }^{2} \mathrm{MF} 2000$ (Vollkraft, Güstrow, Germany): 33\% extracted soy meal, $20 \%$ corn, $17 \%$ wheat gluten, $13 \%$ wheat, $8 \%$ extracted rapeseed meal, $5 \%$ sugar beet pulp, $2 \%$ sodium hydrogen carbonate, $1.3 \%$ calcium carbonate, $0.2 \%$ sodium chloride, $8.0 \mathrm{MJ}$ of $\mathrm{NE}_{\mathrm{L}} / \mathrm{kg}$ of DM, $204 \mathrm{~g}$ of utilizable protein $/ \mathrm{kg}$ of DM.

${ }^{3}$ ATR R 7256 (ATR, Ratzeburg, Germany): $15.30 \%$ calcium, $13.40 \%$ sodium, $5.20 \%$ magnesium, $0.85 \%$ phosphorus, vitamins $\mathrm{A}, \mathrm{D}_{3}, \mathrm{E}$, copper sulfate, zinc oxide, sodium selenite, cobalt carbonate, iron sulfate, and calcium iodate.

${ }^{4}$ Rinderstolz 9522 (Salvana, Sparrieshoop, Germany): 92\% crude ash, $20 \%$ calcium, $5 \%$ phosphorus, $6 \%$ magnesium, $8 \%$ sodium, vitamins A, $D_{3}, E$, copper sulfate, zinc oxide, sodium selenite, cobalt carbonate, iron sulfate, and calcium iodate.

${ }^{5}$ Calculated after German Society of Nutrition Physiology (GfE, 2001). 


\section{Sample Preparation and Determination of VFA, Lactate, and $\mathrm{NH}_{3}$}

Rumen fluid was sieved through a tea strainer to remove feed particles larger than mesh size $(0.3 \mathrm{~mm})$, and the $\mathrm{pH}$ was measured with a glass electrode for 5 s (Roth, Karlsruhe, Germany). The whole process was done within $10 \mathrm{~min}$. Thirty milliliters of filtrate was centrifuged $\left(10 \mathrm{~min}, 4,000 \times g, 4^{\circ} \mathrm{C}\right)$, the supernatant was withdrawn (for metabolite analyses), and the pellet was immediately stored at $-80^{\circ} \mathrm{C}$ for DNA and RNA analyses. Ammonia was determined by microdiffusion and lactate acid was measured colorimetrically, as described previously (Voigt and Steger, 1967). To determine VFA concentration, rumen fluid supernatant (5 mL) was treated with $2 \mathrm{~mL}$ of internal standard (43 $\mathrm{m} M$ isocaproic acid) and centrifuged again (20 min, $\left.12,000 \times g, 4^{\circ} \mathrm{C}\right)$ to apply $1 \mu \mathrm{L}$ of the cleared supernatant to an FFA phase column (25 m, 0.25 ID, $0.32 \mu \mathrm{m})$ mounted on a GC-flame ionization detector (Series 17A; Shimadzu, injector temperature: $225^{\circ} \mathrm{C}$, oven ramp: $110-170^{\circ} \mathrm{C}$ within $7 \mathrm{~min}$ ) according to Ryan (1980).

\section{DNA Extraction}

Total DNA was isolated and purified from 200-mg pellets using the QIAamp DNA stool Mini Kit (Qiagen, Hilden, Germany) following the manufacturer's instructions but modifying the temperature of lysis incubation to $95^{\circ} \mathrm{C}$. The DNA concentration and purity were assessed using a Nanophotometer TM (Implen GmbH, Munich, Germany). All DNA samples were frozen at $-80^{\circ} \mathrm{C}$ before serving as template in quantitative (q) PCR analyses.

\section{RNA Extraction and Transcription Into cDNA}

Frozen pellets were crushed under liquid nitrogen and $100 \mathrm{mg}$ of powder was used for total RNA extraction using TRI reagent (Sigma-Aldrich, Taufkirchen, Germany). Extracts were treated with Baseline-Zero DNase (Epicenter, Madison, WI) and cleaned up using the NucleoSpin RNA XS (Macherey-Nagel, Düren, Germany). The RNA was visualized on $1 \%$ agarose gels containing ethidium bromide to examine RNA integrity. The RNA quantity was determined by Nanophotometer (Implen GmbH, Munich, Germany). Absence of DNA contamination was confirmed using the RNA as a template in standard PCR amplifying fragments of the rrs gene (Weisburg et al., 1991; Hicks et al., 1992). Due to the poor quality of 2 RNA samples, only 17 of 19 samples were available for analysis. All RNA samples were stored at $-80^{\circ} \mathrm{C}$ for further analysis. The RNA samples were reverse transcribed into cDNA using M-MLV reverse transcriptase (Promega, Munich, Germany) according to the manufacturer's protocol.

\section{qPCR Analysis of mcrA and rrs Genes}

Total methanogens were targeted with various specific primers for the mcrA gene (Mlas-mod, Mlas, mcrA). Two rrs primers (TBac, SRV3) were used as reference gene to target total bacteria (Table 2). Primers were purchased from Sigma-Aldrich. The qPCR mixtures for both rrs and mcrA genes contained $5 \mu \mathrm{L}$ of PCR-grade $\mathrm{H}_{2} \mathrm{O}, 0.5 \mu \mathrm{L}$ of forward primer $(10 \mu M)$, $0.5 \mu \mathrm{L}$ of reverse primer $(10 \mu \mathrm{M})$, and $2 \mu \mathrm{L}$ of LightCycler Fast DNA Master Plus SYBR Green I Reaction Mix (Roche Diagnostics, Mannheim, Germany). LightCycler Master Mix was filled in the LightCycler glass capillaries and $2 \mu \mathrm{L}$ of extracted DNA (5 ng/ $\mu \mathrm{L})$ or cDNA $(10 \mathrm{ng} / \mu \mathrm{L})$ were added as a PCR template (total volume of $10 \mu \mathrm{L}$ ). Nontemplate controls were included in each assay. The $\mathrm{qPCR}$ of $\mathrm{rrs}$ and mcrA genes was performed in a LightCycler 2.0 system (Roche Diagnostics). The temperature profiles consisted of initial denaturation at $95^{\circ} \mathrm{C}$ for $10 \mathrm{~min}$, followed by an amplification protocol (Supplementary Table S1; http://dx.doi.org/10.3168/jds.2015-9310) specific for each primer. A melting curve was recorded by measuring the fluorescence between 60 and $95^{\circ} \mathrm{C}$ with a heating rate of $0.1^{\circ} \mathrm{C}$ per second. The intraassay variations were $13.9 \%$ for cDNA and $4.3 \%$ for DNA, respectively. The interassay variation calculated from 2 different runs on separate days were $19.6 \%$ for cDNA and $20.8 \%$ for DNA. To determine specificity of primers, mcrA and rrs PCR products were purified on a $2 \%$ agarose gel containing ethidium bromide and amplicon bands were excised and subsequently purified by a High Pure PCR Product Purification kit (Roche Diagnostics). The efficiency of amplification was calculated by using LinRegPCR software (Ruijter et al., 2013) yielding efficiency values between 1.78 and 1.92 . Amplicons were sequenced on an ABI 3130 Genetic Analyzer (Life Technologies GmbH, Darmstadt, Germany). The obtained sequences were blasted using the NCBI Blast tool (http://blast.ncbi.nlm.nih.gov/Blast. cgi) and findings confirmed sequence identity. The ratio between mcrA and rrs abundances was calculated using the equation published by Pfaffl (2001):

$$
R=\frac{\left(E_{\text {target }}\right)^{\Delta \mathrm{CP} \text { target (control - sample) }}}{\left(E_{\text {ref }}\right)^{\Delta \mathrm{CP} \text { ref (control - sample) }}},
$$


Table 2. Primers used for the quantification of $m c r A^{1}$ and $r r s^{2}$ abundances on DNA and cDNA

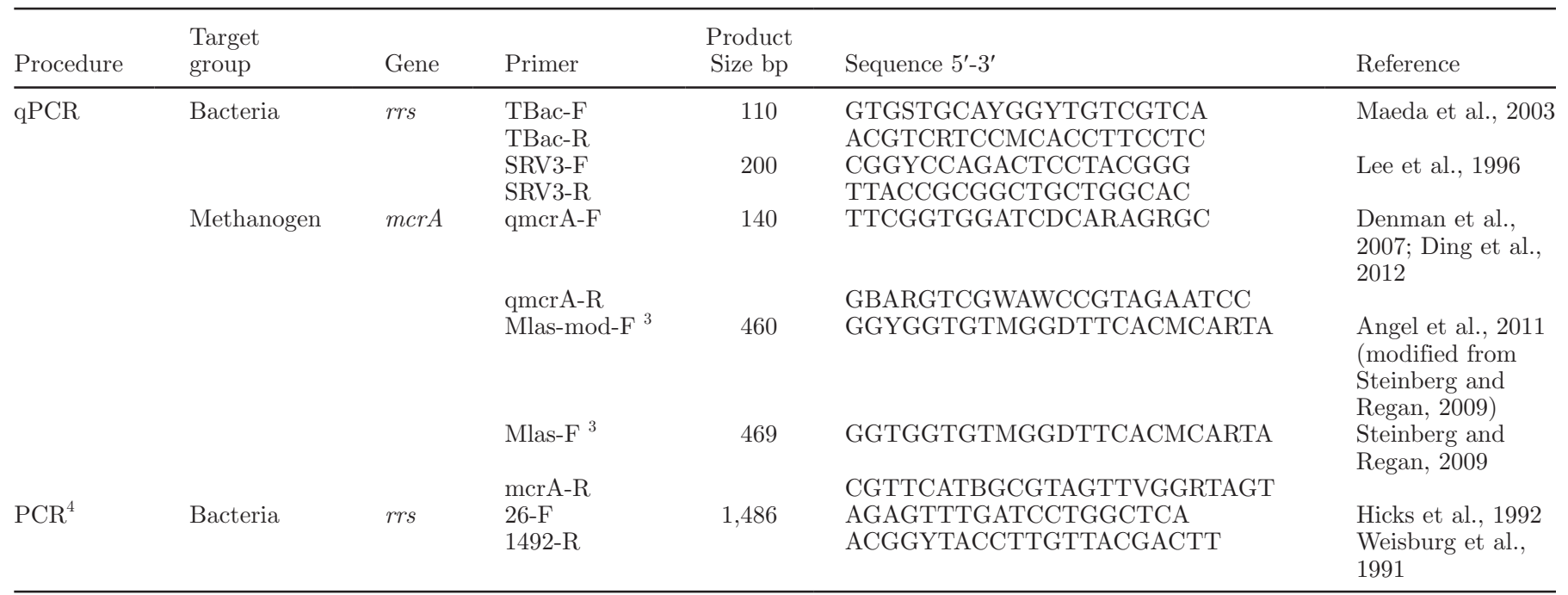

${ }^{1}$ Gene encoding the subunit $\alpha$ of methyl-coenzyme $\mathrm{M}$ reductase.

${ }^{2}$ Gene encoding $16 \mathrm{~S}$ ribosomal RNA.

${ }^{3}$ To combine with $m c r A$-rev primer.

${ }^{4}$ For the detection of DNA contamination in RNA samples.

where $R=$ relative expression ratio of the target gene, $E=$ efficiency, $\mathrm{CP}_{\text {target }}=$ crossing point of the target gene, and $\mathrm{CP}_{r e f}=$ crossing point of the reference gene.

\section{Statistical Analysis}

Normal distribution of data was assessed by means of univariate procedure in SAS (SAS version 9.3, SAS Institute Inc., Cary, NC). To determine the correlations between relative quantity or activity of methanogens in the rumen, methane production, and VFA, the Spearman correlation was applied by the reg and corr procedures of SAS. To determine differences in DMI, milk yield, methane production, rumen $\mathrm{pH}$, and VFA between different diets, the GLM procedure of SAS was used. Statistical significance of model was accepted at $P<0.05$.

\section{RESULTS}

\section{DMI, Milk Yield, and Rumen Fermentation Characteristics}

Dry matter intake and total $\mathrm{CH}_{4}$ production per day did not differ between $\mathrm{HC}$ and $\mathrm{MC}$ diets; however, $\mathrm{CH}_{4}$ yield expressed as liters per kilogram of DMI was significantly lower $(P<0.05)$ when cows received the HC diet (Table 3). As expected, milk yield was lower when cows were offered the MC $\operatorname{diet}(P<0.05)$. The ruminal fluid concentration of acetate and butyrate was greater on the MC diet, whereas the propionate concentration was higher on the $\mathrm{HC}$ diet $(P<0.05)$. Accordingly, the $\left(\mathrm{C}_{2}+\mathrm{C}_{4}\right) / \mathrm{C}_{3}$ ratio was greater when cows were fed the $\mathrm{MC}$ diet $(P<0.05)$. In addition, ranking of individual cows for methane yield was not equivalent on the $\mathrm{HC}$ and $\mathrm{MC}$ diet.

\section{Correlations Between $\mathrm{CH}_{4}$ Yield and mcrA Abundance}

The abundance of methanogens relative to total bacteria in rumen fluid samples was determined to ex-

Table 3. Dry matter intake, milk yield, and fermentation characteristics of rumen fluid from dairy cows fed a high-concentrate (HC) or a medium-concentrate (MC) diet

\begin{tabular}{|c|c|c|c|}
\hline \multirow[b]{2}{*}{ Item } & \multicolumn{2}{|c|}{ Diet } & \multirow[b]{2}{*}{$P$-value } \\
\hline & $\mathrm{HC}$ & $\mathrm{MC}$ & \\
\hline DMI, kg/d & $15.6 \pm 4.2$ & $15.2 \pm 4.7$ & NS \\
\hline Methane, L/d & $494.6 \pm 81.0$ & $550.4 \pm 129.0$ & NS \\
\hline Methane yield, L/kg of DMI & $31.9 \pm 2.4$ & $37.4 \pm 5.4$ & 0.008 \\
\hline Milk, L/d & $32.3 \pm 5.3$ & $24.9 \pm 4.3$ & 0.003 \\
\hline \multicolumn{4}{|l|}{ Rumen VFA, mol \% } \\
\hline Acetate & $51.8 \pm 2.8$ & $55.0 \pm 2.1$ & 0.0121 \\
\hline Propionate & $24.8 \pm 2.7$ & $20.8 \pm 1.0$ & 0.0004 \\
\hline Isobutyrate & $1.0 \pm 0.1$ & $1.3 \pm 0.2$ & 0.0122 \\
\hline Butyrate & $16.9 \pm 1.9$ & $17.4 \pm 1.2$ & NS \\
\hline Isovalerate & $1.7 \pm 0.4$ & $2.0 \pm 0.5$ & NS \\
\hline Valerate & $2.3 \pm 0.5$ & $2.4 \pm 0.3$ & NS \\
\hline Caproate & $0.8 \pm 0.4$ & $0.8 \pm 0.3$ & NS \\
\hline$\left(\mathrm{C}_{2}+\mathrm{C}_{4}\right) / \mathrm{C}_{3}^{1}$ & $2.8 \pm 0.4$ & $3.6 \pm 0.2$ & 0.0004 \\
\hline Lactate & $0.6 \pm 0.5$ & $0.3 \pm 0.37$ & NS \\
\hline Rumen $\mathrm{pH}$ & $6.9 \pm 0.3$ & $7.1 \pm 0.3$ & NS \\
\hline
\end{tabular}

${ }^{1}$ Sum of acetate and butyrate divided by propionate. 
amine whether it reflects methane yield in cows offered diets with different levels of concentrate. To this end, abundance of mcrA DNA relative to the DNA abundance of $r r s$ was analyzed using discrete combinations of primer sets (Table 3 ). When using qmerA primers for the quantification of methanogens, we found significant linear relation between methane yield and relative $m c r A$ abundance after normalization with Tbac (Figure 1A; $\mathrm{r}=0.47, \mathrm{SD}=4.56, P<0.05)$ or after normalization with SVR3 (Figure 1B; $\mathrm{r}=0.47, \mathrm{SD}=4.72, P<0.05$ ) primers. There were no significant correlations between methane yield and mcrA DNA abundance when Mlas primers were used (Figure 1C and 1D). Moreover, use of qmerA primers (Figure 2A; $\mathrm{r}=0.58, \mathrm{SD}=4.76, P$ $<0.05)$ revealed linear correlation between the $m c r A$ DNA copy number and methane yield. In addition, when methane production was expressed as liters per day, no significant correlations with mcrA DNA or with $m c r A$ cDNA were detected (data not shown).

There were no significant correlations between mcrA cDNA abundances and methane yield no matter which of the primer sets was used (Supplementary Figure S1; http://dx.doi.org/10.3168/jds.2015-9310). Also, no correlation with methane yield was found when $\mathrm{mcr} A$ transcript abundance was normalized to $\operatorname{mcr} A$ gene abundance (Supplementary Figure S2), when mcrA gene abundance was normalized to $\operatorname{mcr} A$ transcript abundance (Supplementary Figure S3), or when the mcrA cDNA copy number was used (Supplementary Figure S4). When the regression analysis was performed separately for each diet, no significant correlations could be determined for genomic DNA or for cDNA (data not shown).

\section{Correlations Between VFA or Lactate with $\mathrm{CH}_{4}$ Production and mcrA Abundance}

We found direct correlations between methane yield and molar percentage of acetate, but also with the $\left(\mathrm{C}_{2}+\mathrm{C}_{4}\right) / \mathrm{C}_{3}$ ratio (Table 4$)$. Inverse correlations were found between methane yield and propionate and lactate, respectively (Table 4). In addition, the mcrA DNA abundance correlated significantly with molar percentage of acetate, propionate, (qmcrA/Tbac and qmcrA/SRV3 only), but also with isobutyrate, the $\left(\mathrm{C}_{2}\right.$ $\left.+\mathrm{C}_{4}\right) / \mathrm{C}_{3}$ ratio and with lactate (Table 4). When $\mathrm{mcrA}$ cDNA abundances were used for correlation analyses, significant correlation coefficient values were obtained with isobutyrate, isovalarate, valarate, and lactate (Table 4). When mcrA transcript abundance was normalized to $m c r A$ gene abundance using qmcrA primers, no correlations with VFA were found (data not shown). Also, there were no significant correlations when VFA concentrations were expressed in millimolar.

\section{DISCUSSION}

The aim of the present study was to assess the relationship between $\mathrm{CH}_{4}$ production from Holstein cows and the quantity and activity of methanogens in the rumen. To approach this aim, we tested 3 different primer sets for the quantification of methanogens, but only the application of qmcrA primers revealed significant correlations with methane yield. The specificity of primers could be the reason for such different results. Whereas the Mlas and Mlas-mod primers designed by Steinberg and Regan (2009) were primarily developed for clone library construction and qPCR analyses in oligotrophic fen and anaerobic digester sludge, the qmerA primer set has been widely used to quantify methanogens specifically from the ruminant gastrointestinal tract, which harbors a different methanogen population (Denman et al., 2007). First attempts were made to relate rumen methanogens as quantified by qmerA primers with whole-animal methane production in small ruminants, but the results show some discrepancies (McCartney et al., 2013). Briefly, Ding et al. (2012) reported a highly positive correlation between mcrA DNA abundance and methane yield measured in 12 Tibetan sheep, whereas Morgavi et al. (2012) failed to demonstrate a significant relationship for 6 Texel wethers, which could have been due to defaunation applied in the latter study. Our results are in agreement with the results described by Ding et al. (2012), showing significant correlations between mcrA/rrs DNA abundance and methane yield. The variation of methane yield, and thus the variation of mcrA DNA abundance, might be caused by a shift in the microbial community composition. For example, Shi et al. (2014) reported elevated Methanosphaera spp. in the low- $\mathrm{CH}_{4}$ yield sheep and higher relative abundances of organisms belonging to the Methanobrevibacter gottschalkii clade in the high$\mathrm{CH}_{4}$ yield sheep. Our results are also comparable to the study by Wallace et al. (2014), who described a linear correlation between methane per kilogram of DMI and the ratio of total archaea normalized to total bacterial abundance. Splitting according to the diet, as in our study, revealed that no significant correlation could be seen between methane emission and the relative abundance of methanogens from animals fed a mediumconcentrate diet (Wallace et al., 2014). By contrast, a highly significant correlation between methane emission and the relative abundance of methanogens was found when animals were on a high-concentrate diet (Wallace et al., 2014). The lower number of data obtained from animals on an $\mathrm{HC}$ diet might be one reason why we failed to obtain such a diet-specific relationship. Our results are also comparable to findings described for anaerobic digesters, in which the mcrA gene copy num- 

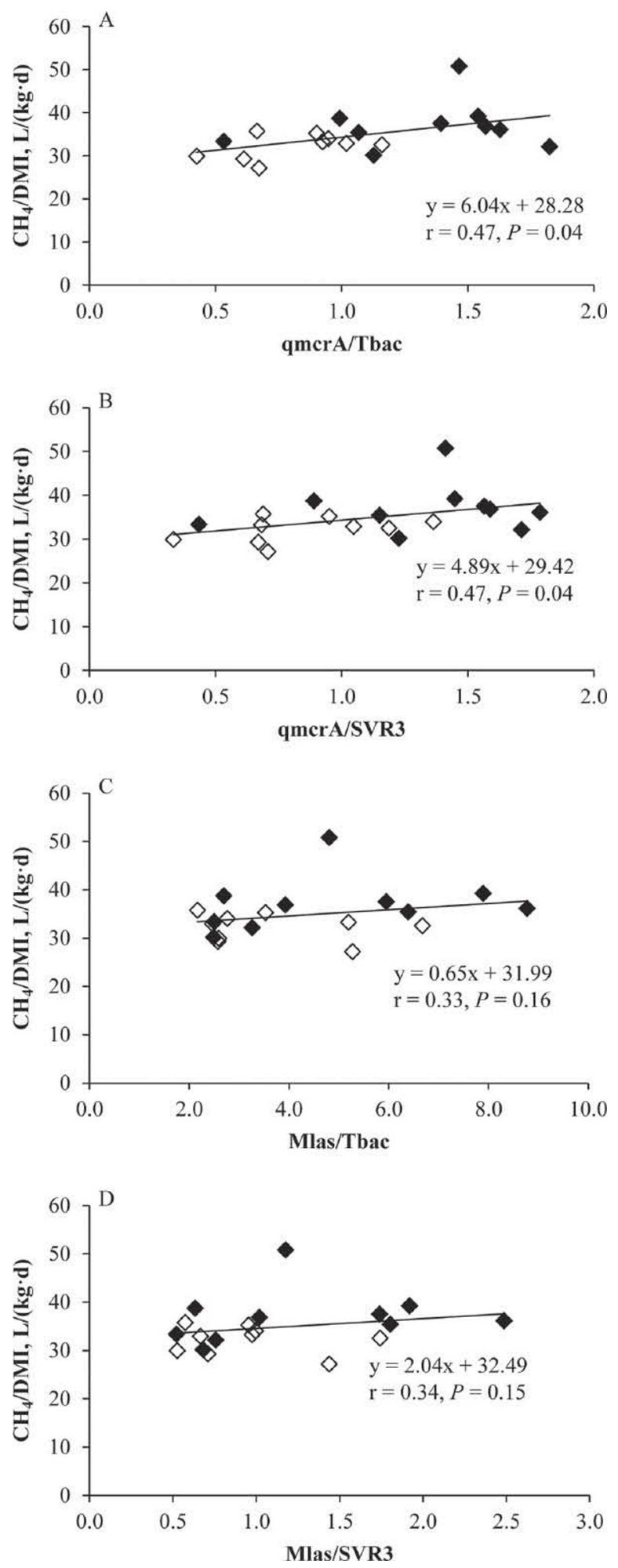

Figure 1. Linear regression between methane emissions per kilogram of DMI per day and mcrA DNA abundance normalized to the rrs. The mcrA DNA abundance was measured using qmcrA (A and B) or Mlas $(\mathrm{C}$ and $\mathrm{D})$ primers, whereas the rrs abundance was measured using TBac (A and C) or SRV3 (B and D) primers. Linear regression equations as well as Spearman correlation coefficients $r$ are provided. $\diamond=$ high-concentrate diet; $\diamond=$ medium-concentrate diet. ber significantly correlated with $\mathrm{CH}_{4}$ production rates, whereas correlations between $m c r A$ transcript number and specific methanogenic activity were not significant (Morris et al., 2014). The $m c r A$-to-rrs ratios shown in Figure 1 were calculated by use of the Pfaffl formula (Pfaffl, 2001), which considers the different efficiency of the primers used for mcrA and rrs quantification. Thus, the mcrA DNA-to-rrs DNA ratio may be greater than 1. By contrast, Wallace et al. (2014) calculated the archaea-to-bacteria ratio based on copy numbers resulting in values lower than 0.2.

However, it has been suggested that the quantification of methanogens via genomic DNA is not specific to active $\mathrm{CH}_{4}$-producing microbes because DNA may also originate from inactive or dead cells (Lettat and Benchaar, 2013). Therefore, cDNA-based analysis is thought to discriminate active microbes from the total microbial community (Lettat and Benchaar, 2013). In support of this assumption, Shi et al. (2014) have recently shown that the transcription of methanogenesis pathway genes was substantially increased in sheep with high methane yield, whereas the abundance of methanogens was not significantly different in high- and low-methane emitters. In the present study, however, we did not observe significant correlations between $m c r A$ cDNA abundance (no matter whether expressed as copy number or normalized with $r r s$ or $\operatorname{mcr} A$ DNA) and methane yield. This might be explained by the fact that only $78 \%$ of the bacteria detected at DNA and cDNA fingerprints were found to be common to total and active bacterial communities (Lettat and Benchaar, 2013). Moreover, differences between DNA and cDNA fingerprints in total and active bacteria may also affect the rrs DNA and rrs cDNA abundance, thereby influencing the $m c r A$-to-rrs ratio. Another reason may be that the mcrA cDNA abundance does not sufficiently reflect the differences in the methane-producing capability per cell. For example, rapidly growing methanogens with low methane-producing activity might explain why the slopes from linear regressions between methane yield and mcrA cDNA abundances expressed as copy numbers or relative to rrs $\mathrm{cDNA}$ or to $m c r A$ DNA, respectively, are much lower (despite not significant) than the slopes obtained from the regression with mcrA DNA abundances. Absence of correlation between cDNA and methane yield may also due to the short half-life of prokaryotic mRNA. For example, the half-life of mcrA transcripts in Methanococcus vannielli at $37^{\circ} \mathrm{C}$ were found to be 15 min (Hennigan and Reeve, 1994), indicating the interference of RNA based approaches as indicator for methane yield. This might be the reason for the divergent results between the present and the results of Shi et al. (2014), which showed that mcrA transcription but not gene abundance corre- 

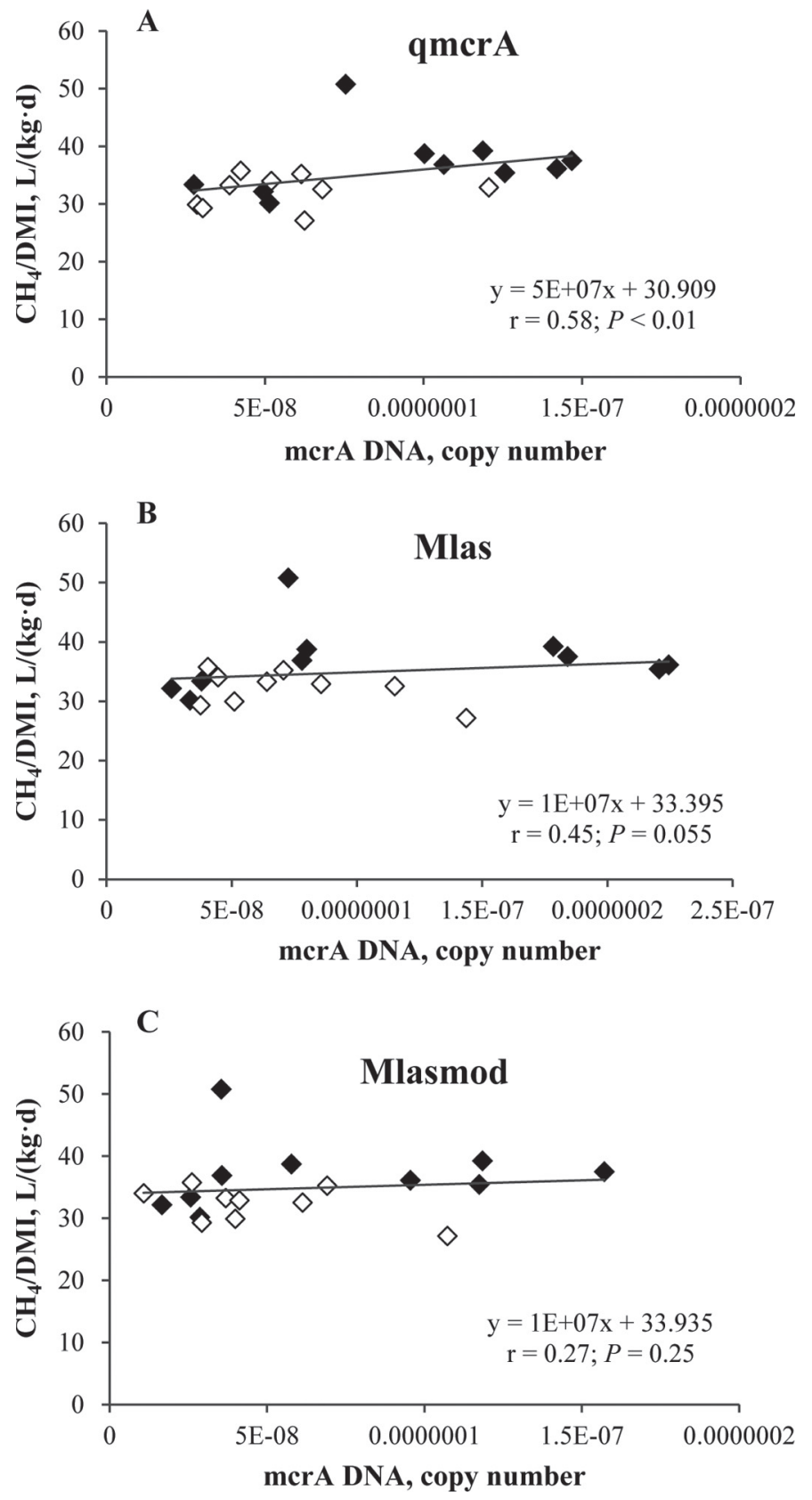

Figure 2. Linear regression between methane emissions per kilogram of DMI per day and copy number of $m c r A$ DNA. The $m c r A$ DNA abundance was measured using qmcrA (A), Mlas primers (B), or Mlasmod (C) primers. Linear regression equations as well as Spearman correlation coefficients $r$ are provided. $\diamond=$ high-concentrate diet; $\diamond=$ medium-concentrate diet.

sponds to 8 sheep, differing by $38.5 \%$ in methane yield. These $m c r A$ transcription differences were directly correlated with the retention time of feed particles and the rumen volume of sheep offered the same diet (Shi et al. 2014). Although we did not measure retention time or rumen volume in the present study, methane production from cows receiving either the $\mathrm{HC}$ or $\mathrm{MC}$ diet varied only by 29 to $34 \%$, which explains some of the discrepancies between the present and the Shi et al. (2014) study. Moreover, nonobserved association between $m c r A$ transcription abundance and methane yield may be due to interindividual differences in the gastrointestinal mucine profile (Hoorens et al., 2011), which is known to affect methanogenesis at least in the colon (Flourié et al., 1991; Gressley et al., 2011).

However, active microbes thought to possess abundant mcrA RNA might only have contributed to the very last period of the 24-h methane measurement, whereas all methanogens, regardless of being dead or alive, might have contributed to gas emission many hours before sampling. Thus, it is important to consider dead, resting, or not fully developed methanogens for quantification, because these methanogens contributed or will contribute to methane production before or after rumen fluid sampling. This highlights the importance of a prompt single rumen fluid sampling relative to $\mathrm{CH}_{4}$ measurement and questions the necessity of long-term methane measurements for the correlation with indicators obtained from a single day of sampling. However, whether data generated from multiple rumen fluid samplings would correlate with multiday methane measurements with a higher regression coefficient needs to be addressed in future studies.

Although the majority of fermentation occurs in the rumen, the hindgut of ruminants contributes to 6 to $14 \%$ of the total $\mathrm{CH}_{4}$ output of cattle (Gressley et al., 2011). We measured whole-animal $\mathrm{CH}_{4}$ production involving ruminal and hindgut-derived methane, but determined only ruminal mcrA abundance. This discrepancy may contribute to a higher standard deviation and lower correlation coefficients values as well. The interception of the regression lines at the y-axis theoretically indicates the amount of methane produced by the hindgut. This would amount to 15 to $30 \mathrm{~L}$ of hindgut methane/ $\mathrm{kg}$ of DMI, which exceeds values known from literature (Gressley et al., 2011). Moreover, Wallace et al. (2014) reported 13 to $14 \mathrm{~L}$ for the interception at the methane yield-axis, indicating that our linear regression model has some weaknesses at lower mcrA-to-rrs ratios. A comparable issue can be seen in the Shi et al. (2014) study, where linear correlation (based on 3 data points) between methane yield and mcrA transcription abundance resulted in a negative value for the interception at the methane yield axis.

Even though the relationship between relative quantity of methanogens estimated by mcrA DNA-based method and methane emission was significant, the existing standard deviaton may refer to the interindividual differences in the rumen methanogen population. Jami and Mizrahi (2012) described the similarities 
Table 4. Spearman correlation coefficient between VFA and lactate concentrations (mol \%) and the abundance of $m c r A$ DNA, $m c r A$ cDNA, and methane emission involving rumen fluid samples obtained from dairy cows fed ad libitum a high-concentrate and medium-concentrate TMR

\begin{tabular}{|c|c|c|c|c|c|c|c|}
\hline \multirow[b]{2}{*}{ Item } & \multicolumn{3}{|c|}{ DNA } & \multicolumn{3}{|c|}{$\mathrm{cDNA}$} & \multirow{2}{*}{$\frac{\mathrm{CH}_{4}}{\mathrm{~L} /(\mathrm{kg} \cdot \mathrm{d})}$} \\
\hline & $q m c r A / T b a c^{1}$ & $q m c r A / S R V 3^{1}$ & $q m c r A^{2}$ & $q m c r A / T b a c^{1}$ & $q m c r A / S R V 3^{1}$ & $q m c r A^{2}$ & \\
\hline Propionate & $-0.628^{* *}$ & $-0.572^{*}$ & -0.402 & -0.244 & -0.291 & 0.232 & $-0.613^{* *}$ \\
\hline Isobutyrate & 0.432 & $0.370^{*}$ & $0.533^{*}$ & $0.753^{* *}$ & $0.750 * *$ & 0.488 & 0.418 \\
\hline Butyrate & -0.011 & -0.051 & -0.168 & -0.365 & -0.374 & -0.188 & 0.202 \\
\hline Isovalarate & 0.142 & 0.063 & 0.221 & $0.685^{* *}$ & $0.594^{*}$ & $0.732^{* *}$ & 0.121 \\
\hline$\left(\mathrm{C}_{2}+\mathrm{C}_{4}\right) / \mathrm{C}_{3}{ }^{3}$ & $0.637^{* *}$ & $0.577^{*}$ & 0.418 & 0.206 & 0.259 & -0.268 & $0.630^{*}$ \\
\hline Lactate & $-0.491^{*}$ & $-0.514^{*}$ & $-0.508^{*}$ & -0.465 & $-0.512^{*}$ & -0.232 & $-0.539^{*}$ \\
\hline
\end{tabular}

${ }^{1}$ Primer sequences provided in Table 2, ratio calculated according to Pfaffl (2001).

2 Primer sequences provided in Table 2, $m c r A$ abundance expressed in unit of copy numbers.

${ }^{3} \mathrm{Sum}$ of acetate and butyrate divided by propionate ( $\left.\mathrm{mol} \%\right)$.

${ }^{*} P<0.05 ;{ }^{* *} P<0.01$.

and differences of the overall bacterial communities of the rumen ecosystem across individual cows fed the same diet with considerable variations between different phyla and bacteria. Moreover, King et al. (2011) found significant differences in the methanogen population structure between Holstein and Jersey cows that were fed the same diet and maintained under the same environmental conditions, suggesting that these differences may be due to host breed genetics.

Another factor influencing the standard deviation may be the composition of the diet fed to the animals. Yáñez-Ruiz et al. (2010) found a higher abundance of methanogens in the rumen of lambs fed only with grass hay than those fed with concentrate and grass hay. Conversely, Lettat and Benchaar (2013) did not observe a diet effect on methanogenic activity in the rumen of lactating Holstein cows fed either barley silage, a 50:50 mixture of barley silage and corn silage, or corn silage only. In our experiment, animals were fed 2 different diets with different proportions of grass and corn silages, but primarily with different amounts of concentrate providing starch. As mentioned before, the different $m c r A$-to-rrs correlations could not be attributed to either of the diets, despite the fact that the contribution of corn starch at the expense of fiber reduces methane production (Jentsch et al., 2007) and causes a different methanogenic species pattern compared with other sources of starch (Beauchemin and McGinn, 2005; Popova et al., 2013).

The molar percentage of VFA has been described to be associated with the amount of methane produced in the rumen. Moss et al. (2000) reported that acetate and butyrate are directly related with methane production, whereas propionate has an inverse relation with methane synthesis as the formation of propionate and methane compete for the nascent hydrogen. Moreover,
Wang et al. (2009) found a reduction of methanogens when the propionic acid concentration in the rumen increased. These findings are consistent with our results presented in Table 4, demonstrating a direct correlation between mcrA DNA abundance and acetate, a direct correlation between $m c r A$ cDNA abundance and isobutyrate, and an inverse correlation between $m c r A$ DNA abundance and propionate.

Lactate, compared with VFA, is a strong acid and produces low $\mathrm{pH}$ values that could explain the inhibition of methane production as it has been reported that rumen $\mathrm{pH}$ affects ruminal methane production (van Kessel and Russell, 1996). The degradation of lactate under anaerobic conditions produces acetate, which in turn shows a significant positive relation with the abundance of mcrA DNA. Furthermore, the production of propionate via lactate reduces the flow of hydrogen to methane (Mitsumori and Sun, 2008), which explains the significantly negative correlation between lactate and methanogens.

\section{CONCLUSIONS}

Herein, we report for the first time correlations between the abundance of the archaeal mcrA gene and methane emissions from the same animals on 2 different diets. A positive significant relationship was found between ruminal mcrA DNA abundance normalized to rrs and methane production per kilogram of DMI, in particular when qmcrA primers were used for the quantification of methanogens. These results highlight the potential usefulness of $m c r A$ DNA as a molecular proxy to estimate methane yield. Nevertheless, reasons for the relatively high standard deviation and low regression coefficients need to be addressed in future studies. 


\section{ACKNOWLEDGMENTS}

We thank the staff at the Tiertechnikum and M. Derno and M. Althaus (Institute of Nutritional Physiology "Oskar Kellner" at FBN Dummerstorf, Germany) for help with respiration trials, rumen fluid sampling, and VFA analyses. This study was financed by the core budget of the Leibniz Institute for Farm Animal Biology (FBN, Dummerstorf, Germany).

\section{REFERENCES}

Angel, R., D. Matthies, and R. Conrad. 2011. Activation of methanogenesis in arid biological soil crusts despite the presence of oxygen. PLoS ONE 6:e20453.

Beauchemin, K. A., and S. M. McGinn. 2005. Methane emissions from feedlot cattle fed barley or corn diets. J. Anim. Sci. 83:653-661.

Belanche, A., M. Doreau, J. E. Edwards, J. M. Moorby, E. Pinloche, and C. J. Newbold. 2012. Shifts in the rumen microbiota due to the type of carbohydrate and level of protein ingested by dairy cattle are associated with changes in rumen fermentation. J. Nutr. 142:1684-1692.

Bhatta, R., O. Enishi, and M. Kurihara. 2007. Measurement of methane production from ruminants. Asian-Australas. J. Anim. Sci. 20:1305-1318

Denman, S. E., N. Tomkins, and C. S. McSweeney. 2007. Quantitation and diversity analysis of ruminal methanogenic populations in response to the antimethanogenic compound bromochloromethane. FEMS Microbiol. Ecol. 62:313-322..

Derno, M., G. Nürnberg, P. Schön, A. Schwarm, M. Röntgen, H. M. Hammon, C. C. Metges, R. M. Bruckmaier, and B. Kuhla. 2013. Short-term feed intake is regulated by macronutrient oxidation in lactating Holstein cows. J. Dairy Sci. 96:971-980.

Ding, X., R. Long, Q. Zhang, X. Huang, X. Guo, and J. Mi. 2012. Reducing methane emissions and the methanogen population in the rumen of Tibetan sheep by dietary supplementation with coconut oil. Trop. Anim. Health Prod. 44:1541-1545.

Flourié, B., P. Pellier, C. Florent, P. Marteau, P. Pochart, and J. C. Rambaud. 1991. Site and substrates for methane production in human colon. Am. J. Physiol. 260:G752-G757.

GfE (German Society of Nutrition Physiology). 2001. Ausschuss für Bedarfsnormen der Gesellschaft für Ernährungsphysiologie, No. 8. Empfehlungen zur Energie- und Nährstoffversorgung der Milchkühe und Aufzuchtrinder (Recommended energy and nutrient supply for dairy cows and growing cattle). DLG-Verlag, Frankfurt am Main, Germany.

Grabarse, W., F. Mahlert, S. Shima, R. K. Thauer, and U. Ermler 2000. Comparison of three methyl-coenzyme M reductases from phylogenetically distant organisms: unusual amino acid modification, conservation and adaptation. J. Mol. Biol. 303:329-344.

Gressley, T. F., M. B. Hall, and L. E. Armentano. 2011. Ruminant nutrition symposium: Productivity, digestion, and health responses to hindgut acidosis in ruminants. J. Anim. Sci. 89:1120-1130.

Hennigan, A. N., and J. N. Reeve. 1994. mRNAs in the methanogenic archaeon Methanococcus vannielii: Numbers, half-lives and processing. Mol. Microbiol. 11:655-670.

Hicks, R. E., R. I. Amann, and D. A. Stahl. 1992. Dual staining of natural bacterio plankton with 4',6-diamidino-2- phenylindole and fluorescent oligonucleotide probes targeting kingdom-level $16 \mathrm{~S}$ rRNA sequences. Appl. Environ. Microbiol. 58:2158-2163.

Hoorens, P. R., M. Rinaldi, R. W. Li, B. Goddeeris, E. Claerebout, J. Vercruysse, and P. Geldhof. 2011. Genome wide analysis of the bovine mucin genes and their gastrointestinal transcription profile. BMC Genomics 12:140.

Jami, E., and I. Mizrahi. 2012. Composition and similarity of bovine rumen microbiota across individual animals. PLoS ONE 7:e33306.
Jentsch, W., M. Schweigel, F. Weissbach, H. Scholze, W. Pitroff, and M. Derno. 2007. Methane production in cattle calculated by the nutrient composition of the diet. Arch. Anim. Nutr. 61:10-19.

Johnson, K. A., and D. E. Johnson. 1995. Methane emissions from cattle. J. Anim. Sci. 73:2483-2492.

King, E. E., R. P. Smith, B. St-Pierre, and A. D. Wright. 2011. Differences in the rumen methanogen populations of lactating Jersey and Holstein dairy cows under the same diet regimen. Appl. Environ. Microbiol. 77:5682-5687.

Knapp, J. R., G. L. Laur, P. A. Vadas, W. P. Weiss, and J. M. Tricarico. 2014. Invited review: Enteric methane in dairy cattle production: Quantifying the opportunities and impact of reducing emissions. J. Dairy Sci. 97:3231-3261.

Leahy, S. C., W. J. Kelly, R. S. Ronimus, N. Wedlock, E. Altermann, and G. T. Attwood. 2013. Genome sequencing of rumen bacteria and archaea and its application to methane mitigation strategies. Animal 7(Suppl. 2):235-243

Lee, D. H., Y. G. Zo, and S. J. Kim. 1996. Nonradioactive method to study genetic profiles of natural bacterial communities by PCRsingle-strand-conformation polymorphism. Appl. Environ. Microbiol. $62: 3112-3120$.

Lettat, A., and C. Benchaar. 2013. Diet-induced alterations in total and metabolically active microbes within the rumen of dairy cows. PLoS One 8:e60978.

Li, L., K. E. Schoenhals, P. A. Brady, C. T. Estill, S. Perumbakkam, and A. M. Craig. 2012. Flaxseed supplementation decreases methanogenic gene abundance in the rumen of dairy cows. Animal 6:1784-1787.

Maeda, H., C. Fujimoto, Y. Haruki, T. Maeda, S. Kokeguchi, M. Petelin, H. Arai, I. Tanimoto, F. Nishimura, and S. Takashiba. 2003. Quantitative real-time PCR using TaqMan and SYBR Green for Actinobacillus actinomycetemcomitans, Porphyromonas gingivalis, Prevotella intermedia, tet $Q$ gene and total bacteria. FEMS Immunol. Med. Microbiol. 39:81-86.

McCartney, C. A., I. D. Bull, and R. J. Dewhurst. 2013. Chemical markers for rumen methanogens and methanogenesis. Animal 7(Suppl. 2):409-417.

Mitsumori, M., and W. Sun. 2008. Control of rumen microbial fermentation for mitigating methane emissions from the rumen. AsianAustralas. J. Anim. Sci. 21:144-154.

Morgavi, D. P., C. Martin, J. F. Jouany, and M. J. Ranilla. 2012. Rumen protozoa and methanogenesis: not a simple cause-effect relationship. Br. J. Nutr. 107:388-397.

Morris, R., A. Schauer-Gimenez, U. Bhattad, C. Kearney, C. A. Struble, D. Zitomer, and J. S. Maki. 2014. Methyl coenzyme M reductase (mcrA) gene abundance correlates with activity measurements of methanogenic $\mathrm{H}_{2} / \mathrm{CO}_{2}$-enriched anaerobic biomass. Microb. Biotechnol. 7:77-84

Moss, A. R., J. P. Jouany, and C. J. Newbold. 2000. Methane production by ruminants: Its contribution to global warming. Ann. Zootech. 49:231-253.

Pfaffl, M. W. 2001. A new mathematical model for relative quantification in real-time RT-PCR. Nucleic Acids Res. 29:e45.

Popova, M., D. P. Morgavi, and C. Martin. 2013. Methanogens and methanogenesis in the rumens and ceca of lambs fed two different high-grain-content diets. Appl. Environ. Microbiol. 79:1777-1786.

Poulsen, M., C. Schwab, B. B. Jensen, R. M. Engberg, A. Spang, N. Canibe, O. Højberg, G. Milinovich, L. Fragner, C. Schleper, W. Weckwerth, P. Lund, A. Schramm, and T. Urich. 2013. Methylotrophic methanogenic thermoplasmata implicated in reduced methane emissions from bovine rumen. Nat. Commun. 4:1428.

Ruijter, J. M., M. W. Pfaffl, S. Zhao, A. N. Spiess, G. Boggy, J. Blom, R. G. Rutledge, D. Sisti, A. Lievens, K. De Preter, S. Derveaux, J. Hellemans, and J. Vandesompele. 2013. Evaluation of qPCR curve analysis methods for reliable biomarker discovery: Bias, resolution, precision, and implications. Methods 59:32-46.

Ryan, J. P. 1980. Determination of volatile fatty acids and some related compounds in ovine rumen fluid, urine, and blood plasma by gas-liquid chromatography. Anal. Biochem. 108:374-384. 
Shi, W., C. D. Moon, S. C. Leahy, D. Kang, J. Froula, S. Kittelmann, C. Fan, S. Deutsch, D. Gagic, H. Seedorf, W. J. Kelly, R. Atua, C. Sang, P. Soni, D. Li, C. S. Pinares-Patiño, J. C. McEwan, P. H. Janssen, F. Chen, A. Visel, Z. Wang, G. T. Attwood, and E. M. Rubin. 2014. Methane yield phenotypes linked to differential gene expression in the sheep rumen microbiome. Genome Res. 24:1517-1525.

Steinberg, L. M., and J. M. Regan. 2009. mcrA-targeted real-time quantitative PCR method to examine methanogen communities. Appl. Environ. Microbiol. 75:4435-4442.

Storm, I. M. L. D., A. L. F. Hellwing, N. I. Nielsen, and J. Madsen. 2012. Methods for measuring and estimating methane emission from ruminants. Animals 2:160-183.

Thauer, R. K. 1998. Biochemistry of methanogenesis: A tribute to Marjory Stephenson. 1998 Marjory Stephenson Prize Lecture. Microbiology 144:2377-2406.

Van Kessel, J. A. S., and J. B. Russell. 1996. The effect of pH on ruminal methanogenesis. FEMS Microbiol. Ecol. 20:205-210.
Voigt, J., and H. Steger. 1967. About the determination of ammonia urea, and ketone bodies in biological material using a modified form of micro diffusion vessel. Arch. Anim. Nutr. 17:289-293.

Wallace, R. J., J. A. Rooke, C. A. Duthie, J. J. Hyslop, D. W. Ross, N. McKain, S. M. de Souza, T. J. Snelling, A. Waterhouse, and R. Roehe. 2014. Archaeal abundance in post-mortem ruminal digesta may help predict methane emissions from beef cattle. Sci. Rep. 4:5892.

Wang, Y., Y. Zhang, J. Wang, and L. Meng. 2009. Effects of volatile fatty acid concentrations on methane yield and methanogenic bacteria. Biomass Bioenergy 33:848-853.

Weisburg, W. G., S. M. Barns, D. A. Pelletier, and D. J. Lane. 1991. $16 \mathrm{~S}$ ribosomal DNA amplification for phylogenetic study. J. Bacteriol. 173:697-703.

Yáñez-Ruiz, D. R., B. Macias, E. Pinloche, and C. J. Newbold. 2010. The persistence of bacterial and methanogenic archaeal communities residing in the rumen of young lambs. FEMS Microbiol. Ecol. $72: 272-278$. 